\title{
Health Literacy and Workplace Safety Climate and Occupational Accidents of Industrial Workers
}

Fahri OZAYDIN ${ }^{1}$, Hakan DEMIRCI ${ }^{2}$, Yusuf KARAYUREK ${ }^{1}$

${ }^{1}$ Esref Dincer Family Health Center, Bursa, TURKEY

${ }^{2}$ Department of Family Medicine, University of Health Sciences Turkey Bursa Yuksek Ihtisas Training and Research Hospital, Bursa, TURKEY

\begin{abstract}
Aim: The aim of this study was to investigate the relationship between occupational accidents of industrial workers, health literacy and workplace safety climate.

Methods: This study was conducted with workers working in the industrial zone of Gemlık, Bursa between August 2020 and December 2020. These individuals were visited in their workplaces. The volunteers were asked to fill out a sociodemographic data form, the Workplace Safety Climate Survey and the Newest Vital Sign Form.

Results: Health literacy level was evaluated among the workers with and without days away from work due to occupational accident and the results were found to be significantly higher for those without days away from work $(p=0.001)$. According to this assessment, total mean score of the Workplace Safety Climate Survey was calculated as $35.45 \pm 10.6$ ( $\min .=20$, max. $=70$ ) for individuals with days away from work due to occupational accident and as $48.82 \pm 7.81$ ( $\min .=27, \max .=70$ ) for participants without occupational accident, and statistically there was a significant difference between them $(p<0.001)$. When the relationship between the Newest Vital Sign Scale and Workplace Safety Climate Survey was analyzed, it was determined that positive safety climate perception of the participants significantly and positively affected their health literacy mean scores $(r=0.294 ; p=<0.001)$.

Conclusions: This study has demonstrated that the health literacy level of employees affects their occupational accident experiences. From this point of view, it may be suggested that employees who work in high risk fields could be chosen from among those with higher health literacy levels. In general terms, the importance of regular trainings for the purpose of decreasing accident rates has been once more shown with this study.
\end{abstract}

Keywords: Occupational accident; Workplace Safety Climate Survey; Newest Vital Sign Scale

Corresponding Author: Fahri OZAYDIN fahri-ozaydin@hotmail.com

Received: April 18, 2021; Accepted: April 22, 2021; Published Online: April 23, 2021

Cite this article as: Ozaydin, F., Demirci, H. \& Karayurek, Y. (2021). Health Literacy and Workplace Safety Climate and Occupational Accidents of Industrial Workers. European Health Literacy Journal 1(1), 45-55. 


\section{Introduction}

Health literacy includes decision making in daily life about health care, self-protection from disease and promotion and improvement of health to preserve or improve the lifelong quality of life, as well as acknowledgement, motivation and competence in accessing, understanding, evaluating and implementing accurate information about health. Health literacy has drawn considerable interest worldwide in recent years. In the $21^{\text {st }}$ century, societies face a decision making problem concerning health. People increasingly have difficulty in making healthy lifestyle choices in their chaotic living environments and in using health care systems, and unfortunately they are not well prepared or supported in the accomplishments of these tasks (1-3).

All countries in the world make various legislative regulations to reduce occupational accidents and deaths caused by accidents. By this means, they try to promote occupational safety. There is a relationship between the safety climate perceived by employees and ongoing occupational accidents. It has been observed that workers who perceive their workplace as safe have less occupational accidents than those who perceive their workplace as dangerous (4-8).

The state of occupational health and safety in a workplace depends on the health literacy level of its employees. According to the definitions of Rauscher and Myers, workplace health literacy is the degree to which individuals have the capacity to obtain, process and understand basic occupational health and safety information and services needed to make appropriate decisions with regard to health and safety at work (9).

In this study, we examined the relationship between health literacy levels of employees and their perception of workplace safety in the prevention of occupational accidents.

\section{METHODS}

This study was conducted with workers from the industrial zone of Gemlik, Bursa between August 2020 and December 2020. These individuals were visited in their workplaces. The volunteers were asked to fill out a sociodemographic data form, the Workplace Safety Climate Survey and the Newest Vital Sign Form.

The University of Health Sciences Turkey Bursa Yuksek Intisas Training and Research Hospital has approved the dissertation entitled: "Relationship of occupational accidents in industrial workers with health literacy and workplace safety climate" with the decision dated 18.03.2020, no 2011-KAEK-25 2020/03-06.

In this study, surveys were distributed to 250 people and 214 accepted to participate.

Inclusion criteria:

Working in the industrial zone of Gemlık, Bursa.

Over age 18.

Accepted to participate in the study.

This was a descriptive study. A face-to-face survey method was used. Workers were visited in their workplaces and were asked to complete a sociodemographic data form, the Newest Vital Sign Form (NVS) and the Workplace Safety Climate Survey.

Sociodemographic Data form: Age, gender, marital status, education level, occupation, monthly income, current residence, smoking status, alcohol usage status, chronic disease history, regular medicine use, days away from work in the most recent year due to occupational accident, and days away from work in the most recent year due to health problems other than occupational accident were questioned.

The Newest Vital Sign Scale: This scale was developed by Weiss et al. in 2005(10). The assessment tool is used in English and Spanish. Its 
Turkish validity and reliability studies were conducted by Ciftci et al. in 2021(11). Cronbach alpha value of the English test is 0.76 and that of the Turkish test is 0.70 . This test comprises six questions in total. The scale is based on the reading, understanding and interpretation ability of the participants about a food label. Each correct answer given is graded as 1 point. It takes about 3-6 minutes to administer the scale. The scale is assessed according to the correct answers given by the participants. Patients with more than 4 correct responses are "unlikely to have low literacy", whereas fewer than 4 correct answers indicate the possibility of limited literacy (12).

Workplace Safety Climate Survey: The safety climate survey was used, which was developed by Choudhry, Fang and Mohamed (13) and validated by Turen et al. (14). It comprises 2 aspects and 14 questions.

Tablo 1:Katılımcıların Genel Özellikleri

\section{Statistical Analysis}

In this study we used number and related percentages for categorical data and descriptive statistical values such as mean, standard deviation, median, minimum and maximum for discrete and continuous data to assess the participants' demographic characteristics, Newest Vital Sign Test NVS Scale and Workplace Safety Climate Survey scores. Chi-square, Fisher's exact chi-square, Fisher-Freeman-Halton and Mann Whitney $U$ tests were used in statistical analysis. SPSS (IBM Corp. Released 2016. IBM SPSS Statistics for Windows, Version 24.0. Armonk, NY: IBM Corp.) program was used for statistical analysis and type I error performance was accepted as 5\%.

\section{RESULTS}

The mean age of the participants evaluated in the research was $39.77 \pm 10.25$ years. $204(95.3 \%)$ of the participants were male and $10(4.7 \%)$ were female (Table1)

\begin{tabular}{|c|c|c|c|}
\hline \multirow[t]{5}{*}{ AGE } & \multicolumn{2}{|l|}{ Mean } & 39.77 \\
\hline & \multicolumn{2}{|c|}{ Standard Deviation } & 10.25 \\
\hline & \multicolumn{2}{|l|}{ Median } & 40.00 \\
\hline & \multicolumn{2}{|c|}{ Minimum } & 18.00 \\
\hline & \multicolumn{2}{|c|}{ Maximum } & 62.00 \\
\hline \multirow[t]{4}{*}{ GENDER } & \multirow[t]{2}{*}{ Female } & Number & 10 \\
\hline & & $\%$ & 4.7 \\
\hline & \multirow[t]{2}{*}{ Male } & Number & 204 \\
\hline & & $\%$ & 95.3 \\
\hline \multirow[t]{4}{*}{ MARITAL STATUS } & \multirow[t]{2}{*}{ Single } & Number & 45 \\
\hline & & $\%$ & 21.0 \\
\hline & \multirow[t]{2}{*}{ Married } & Number & 169 \\
\hline & & $\%$ & 79.0 \\
\hline
\end{tabular}




\begin{tabular}{|c|c|c|c|}
\hline \multirow[t]{6}{*}{ EDUCATION } & \multirow[t]{2}{*}{ Primary Education } & Number & 102 \\
\hline & & $\%$ & 47.7 \\
\hline & \multirow[t]{2}{*}{ High School } & Number & 91 \\
\hline & & $\%$ & 42.5 \\
\hline & \multirow[t]{2}{*}{ University } & Number & 21 \\
\hline & & $\%$ & 9.8 \\
\hline \multirow[t]{4}{*}{ OCCUPATION } & \multirow[t]{2}{*}{ Blue Collar } & Number & 186 \\
\hline & & $\%$ & 86.9 \\
\hline & \multirow[t]{2}{*}{ White Collar } & Number & 28 \\
\hline & & $\%$ & 13.1 \\
\hline \multirow[t]{6}{*}{ INCOME LEVEL } & \multirow[t]{2}{*}{$240-360 \$$} & Number & 157 \\
\hline & & $\%$ & 73.4 \\
\hline & \multirow[t]{2}{*}{$360-600 \$$} & Number & 46 \\
\hline & & $\%$ & 21.5 \\
\hline & \multirow[t]{2}{*}{$600 \$+$} & Number & 11 \\
\hline & & $\%$ & 5.1 \\
\hline \multirow[t]{6}{*}{ RESIDENCE } & \multirow[t]{2}{*}{ Village/Town } & Number & 21 \\
\hline & & $\%$ & 9.8 \\
\hline & \multirow[t]{2}{*}{ County Town } & Number & 184 \\
\hline & & $\%$ & 86.0 \\
\hline & \multirow[t]{2}{*}{ City Center } & Number & 9 \\
\hline & & $\%$ & 4.2 \\
\hline \multirow[t]{4}{*}{ SMOKING } & \multirow[t]{2}{*}{ Yes } & Number & 87 \\
\hline & & $\%$ & 40.7 \\
\hline & \multirow[t]{2}{*}{ No } & Number & 127 \\
\hline & & $\%$ & 59.3 \\
\hline \multirow[t]{4}{*}{ ALCOHOL } & \multirow[t]{2}{*}{ Yes } & Number & 178 \\
\hline & & $\%$ & 83.2 \\
\hline & \multirow[t]{2}{*}{ No } & Number & 36 \\
\hline & & $\%$ & 16.8 \\
\hline
\end{tabular}


The NVS score associated variables and their correlation levels are shown in Table 2. Statistically, NVS scores of males, singles, university graduates, white collar employees, those with high income level, living in the city center, non-smokers and those who did not use alcohol were significantly higher.

Tablo2. Assessment of participants' Newest Vital Sign scale (NVS) scores

\begin{tabular}{|c|c|c|c|c|c|c|c|}
\hline & \multicolumn{5}{|c|}{ TOTAL NVS } & \multirow[b]{2}{*}{$\mathrm{p}$} \\
\hline & & Mean & $\begin{array}{c}\text { Standard } \\
\text { Deviation }\end{array}$ & Median & Minimum & Maximum & \\
\hline \multirow[t]{2}{*}{ GENDER } & Female & .20 & .42 & .00 & .00 & 1.00 & 0.004 \\
\hline & Male & 2.32 & 2.19 & 2.00 & .00 & 6.00 & \\
\hline \multirow[t]{2}{*}{ MARITAL STATUS } & Single & 2.84 & 2.19 & 3.00 & .00 & 6.00 & 0.023 \\
\hline & Married & 2.06 & 2.16 & 2.00 & .00 & 6.00 & \\
\hline \multirow[t]{3}{*}{ EDUCATION LEVEL } & Primary Education & 1.28 & 1.70 & .00 & .00 & 6.00 & $<0.001$ \\
\hline & High School & 2.75 & 2.13 & 3.00 & .00 & 6.00 & \\
\hline & University & 4.52 & 2.14 & 5.00 & .00 & 6.00 & \\
\hline \multirow[t]{2}{*}{ OCCUPATION } & Blue collar & 1.96 & 2.05 & 2.00 & .00 & 6.00 & $<0.001$ \\
\hline & White collar & 4.00 & 2.28 & 5.00 & .00 & 6.00 & \\
\hline \multirow[t]{3}{*}{ INCOME LEVEL } & $2000-3000$ & 1.76 & 1.96 & 1.00 & .00 & 6.00 & $<0.001$ \\
\hline & $3000-5000$ & 3.04 & 2.26 & 4.00 & .00 & 6.00 & \\
\hline & $5000+$ & 5.36 & 1.21 & 6.00 & 2.00 & 6.00 & \\
\hline \multirow[t]{3}{*}{ SETTLEMENT } & Village/town & 1.14 & 1.65 & .00 & .00 & 6.00 & $<0.001$ \\
\hline & County town & 2.21 & 2.13 & 2.00 & .00 & 6.00 & \\
\hline & City center & 5.11 & 2.03 & 6.00 & .00 & 6.00 & \\
\hline \multirow[t]{2}{*}{ SMOKING } & No & 2.76 & 2.24 & 3.00 & .00 & 6.00 & 0.003 \\
\hline & Yes & 1.86 & 2.08 & 1.00 & .00 & 6.00 & \\
\hline \multirow[t]{2}{*}{ ALCOHOL } & No & 2.42 & 2.15 & 2.00 & .00 & 6.00 & 0.003 \\
\hline & Yes & 1.28 & 2.12 & .00 & .00 & 6.00 & \\
\hline
\end{tabular}

SCS score associated variables and their correlation levels are shown in Table 3. No difference was detected between groups in terms of gender, smoking and alcohol usage. 
Tablo3. Assessment of participants' Safety Climate Scale (SCS) scores

\begin{tabular}{|c|c|c|c|c|c|c|c|}
\hline & & \multicolumn{5}{|c|}{ SCS } & \multirow[b]{2}{*}{$\mathrm{P}$} \\
\hline & & Mean & $\begin{array}{l}\text { Standard } \\
\text { Deviation }\end{array}$ & Median & Minimum & Maximum & \\
\hline \multirow[t]{2}{*}{ GENDER } & Female & 49.30 & 4.00 & 48.00 & 46.00 & 60.00 & 0.619 \\
\hline & Male & 46.17 & 10.05 & 48.00 & 20.00 & 70.00 & \\
\hline \multirow[t]{2}{*}{ MARITAL STATUS } & Single & 50.07 & 8.92 & 51.00 & 32.00 & 70.00 & 0.006 \\
\hline & Married & 45.32 & 9.89 & 48.00 & 20.00 & 70.00 & \\
\hline \multirow[t]{3}{*}{ EDUCATION LEVEL } & Primary School & 43.20 & 9.24 & 45.00 & 20.00 & 60.00 & $<0.001$ \\
\hline & High School & 48.16 & 9.56 & 50.00 & 24.00 & 70.00 & \\
\hline & University & 53.48 & 8.65 & 55.00 & 32.00 & 65.00 & \\
\hline \multirow[t]{2}{*}{ OCCUPATION } & Blue collar & 45.32 & 9.69 & 48.00 & 20.00 & 70.00 & $<0.001$ \\
\hline & White collar & 52.96 & 8.50 & 55.00 & 32.00 & 65.00 & \\
\hline \multirow[t]{3}{*}{ INCOME LEVEL } & $240-360$ & 45.00 & 10.12 & 47.00 & 20.00 & 70.00 & 0.002 \\
\hline & $360-600$ & 49.09 & 7.80 & 49.50 & 27.00 & 65.00 & \\
\hline & $600+$ & 53.55 & 9.02 & 55.00 & 32.00 & 65.00 & \\
\hline \multirow[t]{3}{*}{ RESIDENCE } & Village/town & 40.38 & 11.21 & 38.00 & 24.00 & 60.00 & 0.001 \\
\hline & County town & 46.60 & 9.44 & 48.00 & 20.00 & 70.00 & \\
\hline & City center & 54.33 & 8.49 & 55.00 & 34.00 & 65.00 & \\
\hline \multirow[t]{2}{*}{ SMOKING } & No & 46.62 & 9.24 & 49.00 & 25.00 & 67.00 & 0.538 \\
\hline & Yes & 46.11 & 10.31 & 48.00 & 20.00 & 70.00 & \\
\hline \multirow[t]{2}{*}{ ALCOHOL } & No & 46.37 & 9.74 & 48.00 & 20.00 & 70.00 & 0.907 \\
\hline & Yes & 46.06 & 10.63 & 48.50 & 24.00 & 65.00 & \\
\hline
\end{tabular}

Total NVS mean score and number of occupational accidents are given in Table 4 and Figure1. Statistically, a significant relationship was detected between NVS and number of occupational accidents. Similarly, the relationship of total SCS mean score and occupational accident status is given in Table 4 and Figure 2. Number of occupational accidents was lower in those with low SCS mean score. 
Tablo4. Safety Climate Scale and NVS mean scores with occupational accidents

\begin{tabular}{|c|c|c|c|c|}
\hline & & & TOTAL SCS & TOPLAM NVS \\
\hline \multirow[t]{10}{*}{ Occupational accident } & \multirow[t]{5}{*}{ No } & Mean & 48.82 & 2.55 \\
\hline & & Standard Deviation & 7.81 & 2.20 \\
\hline & & Median & 49.00 & 3.00 \\
\hline & & Minimum & 27.00 & .00 \\
\hline & & Maximum & 70.00 & 6.00 \\
\hline & \multirow[t]{5}{*}{ Yes } & Mean & 35.45 & .82 \\
\hline & & Standard Deviation & 10.60 & 1.47 \\
\hline & & Median & 32.00 & .00 \\
\hline & & Minimum & 20.00 & .00 \\
\hline & & Maximum & 70.00 & 5.00 \\
\hline & $\mathrm{p}$-value & & $<0.001$ & $<0.001$ \\
\hline
\end{tabular}

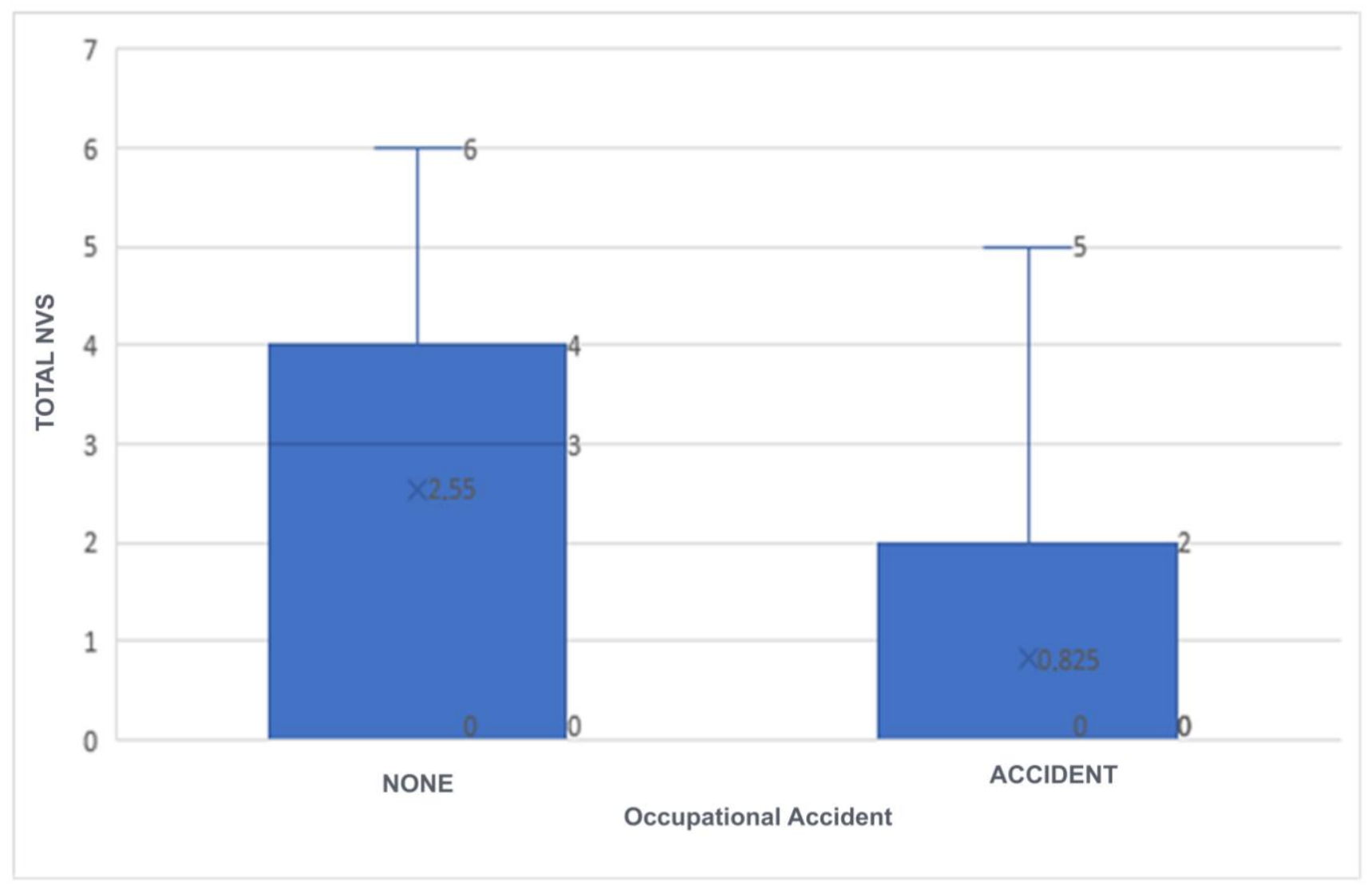

Figure 1. Total NVS mean score versus occupational accident occurrence. 


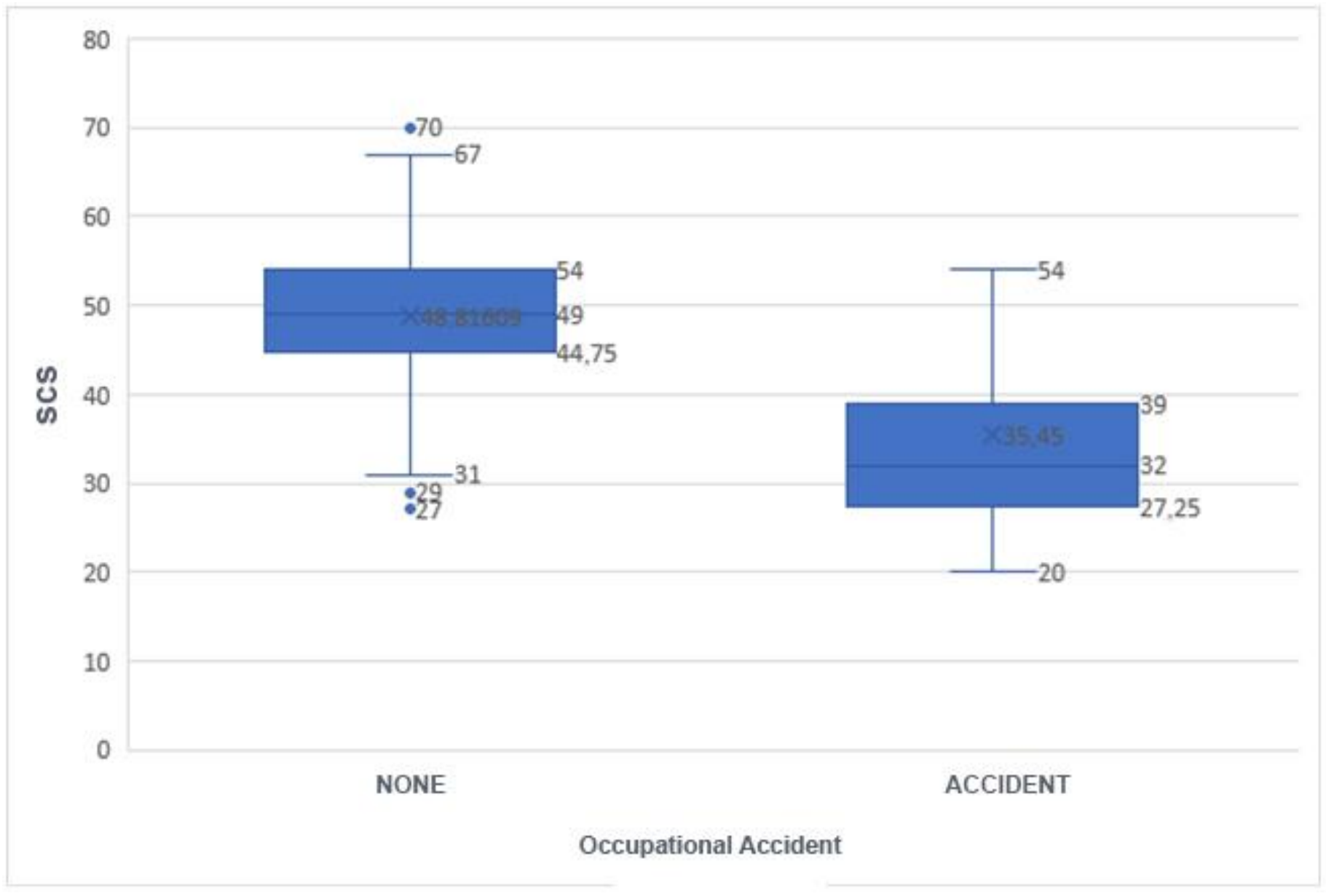

Figure2. Safety Climate Scale mean score versus occupational accident occurrence

As a result of the correlation analysis between the total Newest Vital Sign scale score (NVS) and the total Safety Climate Scale (SCS) score, it has been identified that positive safety climate perception of the participants significantly affected their health literacy mean scores in a positive manner $(r=0.294$; $\mathrm{p}=<0.001$ ) (Figure 3 ). 


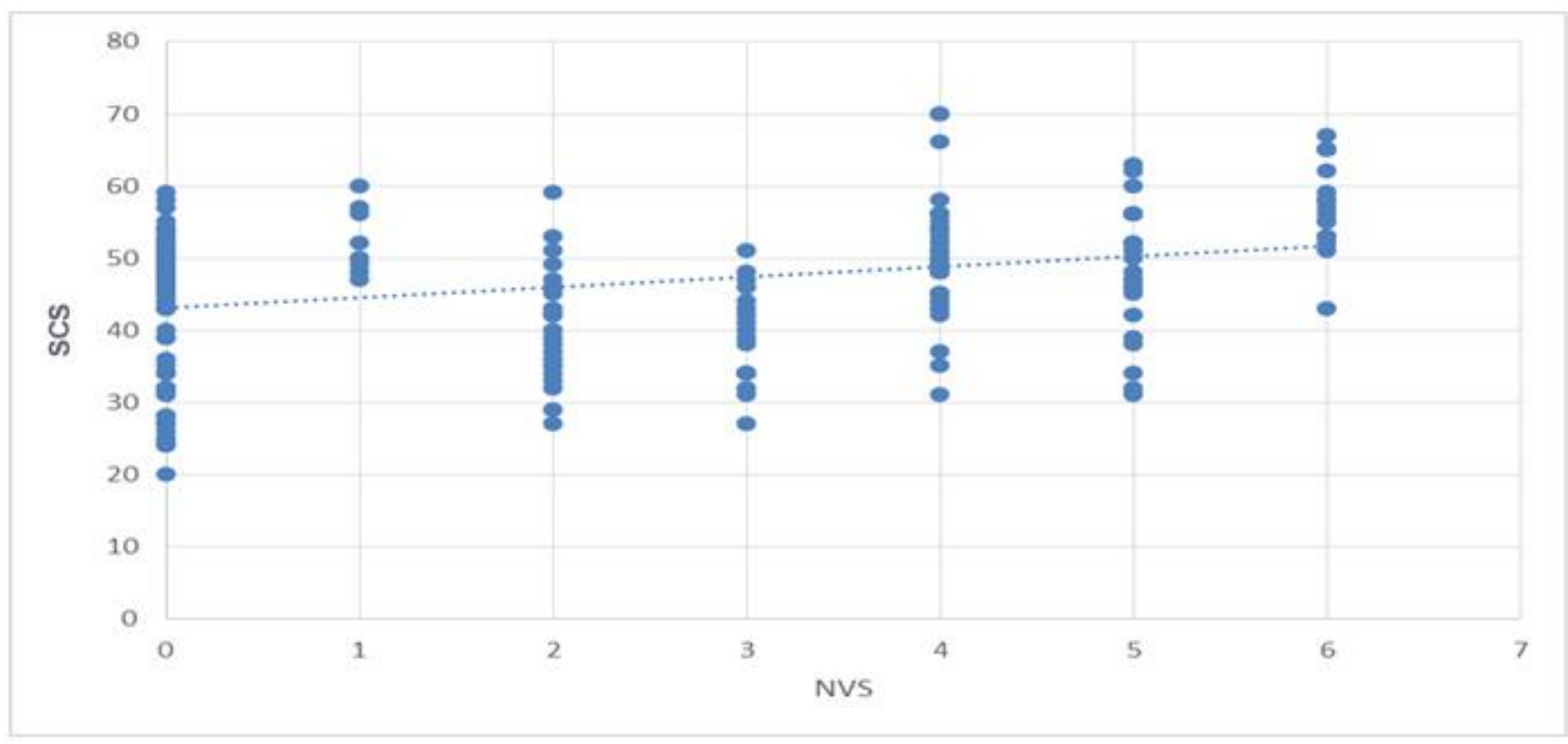

Figure3. Correlation analysis graph of Newest Vital Sign (NVS) and Safety Climate Scale (SCS)

\section{DISCUSSION}

Considering the results of our study, it has been observed that participants with high health literacy had less occupational accidents within the last year. Whereas, according to SCS scores, occupational accidents and participants' safety perceptions were inversely correlated. In our study, as a result of the correlation analysis between total NVS score and total workplace safety climate scale scores, it has been observed that those with high health literacy levels have higher perception of workplace safety.

When our study results are examined, it can be seen that participants with high health literacy had less occupational accidents in the recent year. Unlike our study, in a dissertation study conducted in Suleyman Demirel University Faculty of Medicine, no correlation was detected between occupational accidents and health literacy levels (15). There are not enough studies in the literature on this subject. Researchers assume that one of the reasons for the high prevalence of occupational accidents and diseases is "attention deficit among factors affecting prevention" $(16,17)$. One of the factors affecting health promotion and prevention of occupational accidents and diseases is health literacy (18). We think that in new studies to be performed to analyze the causes of occupational accidents, the frequency of having accidents will decrease with an increase in health literacy level.

Safety climate total mean scores of the participants who had been away from work due to occupational accidents within the last year and those who didn't have occupational accidents were assessed. According to this assessment, statistically, total SCS mean scores of the participants who had been away from work due to occupational accidents were significantly lower compared to those who didn't have occupational accidents. In a study conducted by Karadal et al. in 2017(19), the relationship between safety climate, safety culture and workplace injuries was analyzed. In this study, similar to ours, a negative relationship was found between safety climate and workplace injuries (19).

As a result of the correlation analysis performed in our study between total Newest Vital Sign (NVS) scores and total workplace safety climate scale scores, it has been observed that those with high health literacy 
level had higher workplace safety perception. In several studies, it has been seen that health literacy level increases in parallel with education level, as in our study $(20,21)$. In our study and in another study conducted in the Afyon marble sector, it has been found that workplace safety perception increases with the increase of education level (22). When the results of these studies are considered, a perception of high workplace safety climate of those with high health literacy levels is an acceptable result.

\section{Limitations}

This study in which we examined the relationship between health literacy level and workplace safety climate perception of employees in prevention of occupational accidents is pioneering research on this subject. The strength of the study was calculated as $99 \%$ according to strength analysis, which is a sufficient level. 214 (85\%) of the employees who had been given questionnaires for the study completed the surveys.

A limitation of the study was that it was conducted in only one district of a province. It is probable that there would be regional differences as well in inter-city differences in multi-centered studies.

Interviews with the participants were performed with a face-to-face technique. Participants may have tended not to share their private information during interviews. Although we have paid the utmost attention to the protection of personal information in our research, there is a possibility that some specific information could not be obtained.

\section{CONCLUSION}

The most important result of our study was that the participants with high health literacy levels were exposed to less occupational disease within the last one year. Similarly, those with high health literacy had high workplace safety perception. Another important result of our study was that those with high workplace safety perception had less occupational accidents. Studies to increase the health literacy levels of individuals must be conducted in all fields of life, notably in workplaces. Educational activities are among the most important of these studies. Increase of workplace safety perception of employees can be provided by their active participation in occupational health and safety activities. Regular organization of occupational health and safety trainings by employers to increase employee awareness and taking precautions to avoid occupational accidents will increase the safety perception of the employees.

Taking these factors into consideration could make it possible to reduce occupational accidents. This is one of the few reports on this topic and further studies are needed.

\section{CONFLICT OF INTEREST}

The authors declare that there is no conflict of interest.

\section{References}

1. Nutbeam D. Health promotion glossary. Health Promot. Int. (1998) 13 (4): 349-364.)

2. Health literacy program. http://www.amaassn.org/ama/pub/about-ama/amafoundation/ourprograms/public-health/healthliteracyprogram.page,Erişim tarihi: 07.01.2021

3. Glossary of Health Promotion and promotion. http://apps.who.int/iris/bitstream/10665/64546/3/978 97 903613_tur.pdf, Erişim tarihi: 07.01.2021

4. Hayes vd., 1998; hayes, b. e., perander, j., smecko, t. ve trask, j. (1998). -Measuring Perceptions of Workplace Safety: Development and Validation of The Work Safety Scale\|l, Journal of Safety Research, 29(3), 145-161.

5. Varonen ve Matilla, 2000; varonen, u. ve mattila, m. (2000). - The Safety Climate and Its Relationship To Safety Practices, Safety of The Work Environment and Occupational Accidents in Eight Wood-Processing Companies\|, Accident Analysis \& Prevention, 32(6): 761769. 
6. Mearns, Whitaker ve Flin, 2003 : mearns, k., whitaker, s. m. ve flin, r. (2003). Safety Climate, Safety Management Practice and Safety Performance In Offshore Environments|| Safety Science, 41(8): 641680.

7. Clarke, 2006: clarke s. (2006). The Relationship Between Safety Climate and Safety Performance: A Meta-Analytic Review\|l, Journal of Occupational Health Psychology, 11(4):31527.

8. Guastello, 1992: guastello, s.j. (1992). Accidents and Stress-related Health Disorders Among Bus Operators: Forecasting With Catastrophe Theory\|l. In J.C. Quick, L.R. Murphy, ve J.J. Hurrell, Jr. (Eds.), Stress and Well-Being At Work (pp. 252-269)

9. Rauscher KJ, Myers DJ. Occupational health literacy and work-related injury among US adolescents. Int J Inj Contr Saf Promot [Internet]. 2014;21(1):81-9. Available from:

http://dx.doi.org/10.1080/17457300.2013.792288

10. Weiss BD, Palmer R. Relationship between health care costs and very low literacy skills in a medically needy and indigent Medicaid population. J Am Board Fam Pract 2004;17:44-7.

11.Fatih ÇİFTÇİ, Hakan DEMİRCİ, Hilal Nemli ÇİFTÇİ, Gökhan OCAKOĞLU Validation of Turkish Version of Newest Vital Sign Scale to Assess Health Literacy Bezmialem Science 2021;9(2):219-25

12. Ozdemir $H$, Alper $Z$, Uncu $Y$, Bilgel $N$. Health literacy among adults: a study from Turkey. Health Educ Res. 2010;25(3):464-77

13.CHOUDHRY, R.M., FANG, D., ve LINGARD, $H$. (2009). - Measuring Safety Climate of A Construction Companyll, Journal of Construction Engineering and Management, 135(9): 890-899.

14.Türen, U., Gökmen, Y., Tokmak, İ. \& Bekmezci, M. (2014). Validity and reliability study of the security climate scale, Journal of Economics and Administrative Sciences, 19(4), 171-190.

15. http://tez.sdu.edu.tr/Tezler/TT01281.pdf (Last access 13.02.2021)

16. Karimy M, Niknami S, Hidarnia AR, Hajizadeh I. Intention to start smoking among Iranian male adolescents: the utility of an expanded version of the planned behavior theory. 2012; 4 : 120-4.

17. Escudero DVS, Furtado GHC, Medeiros EA. Compliance of health workers with follow-up after occupational exposure to blood and bodily fluids at a Teaching Hospital in Brazil.Ann Occup Hyg. 2015; 59 : 566-71

18. Beauchamp A, Buchbinder R, Dodson S. vd. The distribution of health literacy strengths and weaknesses among socio-demographic groups: the Health Literacy Survey (HLQ) is a cross-sectional survey using BMC Public Health 2015; 15 : 678

19. Karadal, H , Merdan, E . (2017). the role of safety climate and safety culture on workplace injuries. International Journal of Management Economics and business, 13 (13) , 912-919 . Retrieved from https://dergipark.org.tr/en/pub/ijmeb/issue/54601/744 $\underline{532}$

20. The European Health Literacy Project, 2009- 2012. Comperative Report on Health Literacy in eight EU Member States, Maastricht, HLS-EU Consortium, 2012. www.healthliteracy.eu (Last access 13 Şubat 2021)

21. Özdemir, H., Alper, Z., Uncu, Y., \& Bilgel, N. Health literacy among adults: a study from Turkey. Health Education Research, 2010; 25 (3): p. 464477.

22.Yörük Karakılıç, N , Barın, N . (2019). Effects Of Management Culture On Security Climate: An Application In Afyon Marble Sector .The journal of behavior at work , 4 (2) , 88-97 . DOI: $10.25203 /$ idd. 661121 